\title{
Correction to: Effect of maturation time on dormancy and germination of Citrullus colocynthis (Cucurbitaceae) seeds from the Arabian hyper-arid deserts
}

Ali El-Keblawy ${ }^{1,2^{*}}$, Hatem A. Shabana ${ }^{3,4}$, Teresa Navarro ${ }^{4}$ and Sameh Soliman ${ }^{5}$

\section{Correction}

Following publication of the original article [1] author Hatem Shabana wrote to say that one of her affiliations was missing. The affiliation is as follows:

Departmento de Biología Vegetal, Universidad de Málaga,

P. O. Box 59, 29080 Málaga, Spain

\begin{abstract}
Author details
'Department of Applied Biology, Faculty of Science, University of Sharjah, P. O. Box, 27272 Sharjah, United Arab Emirates. ${ }^{2}$ Department of Biology, Faculty of Science, Al-Arish University, Al-Arish, Egypt. ${ }^{3}$ Sharjah Seed Bank and Herbarium, Sharjah Research Academy, P.O. Box 60999, Sharjah, United Arab Emirates. ${ }^{4}$ Departmento de Biología Vegetal, Universidad de Málaga, P. O. Box 59, 29080 Málaga, Spain. ${ }^{5}$ Department of Medicinal Chemistry, College of Pharmacy, University of Sharjah, P. O. Box, 27272 Sharjah, United Arab Emirates.
\end{abstract}

Received: 13 March 2018 Accepted: 13 March 2018

Published online: 20 March 2018

\section{Reference}

1. El-Keblawy A, Shabana HA, Navarro T, Soliman S. Effect of maturation time on dormancy and germination of Citrullus colocynthis (Cucurbitaceae) seeds from the Arabian hyper-arid deserts. BMC Plant Biol. 2017;17:263. https://doi.org/10.1186/s12870-017-1209-x.

\footnotetext{
* Correspondence: akeblawy@sharjah.ac.ae

'Department of Applied Biology, Faculty of Science, University of Sharjah, P.

O. Box, 27272 Sharjah, United Arab Emirates

${ }^{2}$ Department of Biology, Faculty of Science, Al-Arish University, Al-Arish,

Egypt

Full list of author information is available at the end of the article
} 